\title{
Neonatal necrotizing enterocolitis rat model attenuated by a remote ischemic preconditioning in the pregnant ${ }^{1}$
}

\author{
Rúdnei de Oliveira Luciano Gomes', Ricardo Artigiani Neto", José de Freitas Guimarães Neto', \\ Adriana Porto Nunes', Edna Frasson de Souza Montero'", José Luiz Martins ${ }^{\text {IV }}$
}

\begin{abstract}
'Fellow PhD degree, Postgraduate Program in Interdisciplinary Surgical Science, Universidade Federal de São Paulo (UNIFESP), Sao Paulo-SP, Brazil. Design of the study, acquisition and interpretation of data, manuscript writing.

"Associate Professor, Department of Pathology, UNIFESP, Sao Paulo-SP, Brazil. Histopathological examinations.

I'Associate Professor, Department of Surgery, Laboratory of Surgical Physiopathology (LIM-62), School of Medicine, Universidade de São Paulo (USP), and Department of Surgery, UNIFESP, Sao Paulo-SP, Brazil. Intellectual and scientific content of the study, critical revision.

IVFull Professor, Department of Pediatric Surgery, UNIFESP, Sao Paulo-SP, Brazil. Conception and design of the study, critical revision.
\end{abstract}

\section{Abstract}

Purpose: To evaluate the effect of remote ischemic preconditioning ( $r$-IPC) administered to pregnant rats, in the ileum of newborn rats subjected to hypoxia and reoxygenation.

Methods: We used three pregnant rats and their newborn rats distributed in three groups: 1) Control (C) - Newborn rats born from a pregnant rat which did not undergo any intervention; 2) Hypoxia-Reoxygenation $(H / R)$ - Newborn rats born from a pregnant rat which did not undergo any intervention, and were subjected to hypoxia-reoxygenation; 3 ) Remote Ischemic Preconditioning ( $r$-IPC) - newborn rats born from a pregnant rat which was subjected to remote ischemic preconditioning twenty-four hours before giving birth and the newborn rats were subjected to hypoxia-reoxygenation. Segments of ileum were prepared for histological analysis by $\mathrm{HE}$ and immunohistochemistry by the Ki67 to evaluate cell proliferation, crypt depth and villus height and evaluation of apoptosis by cleaved caspase-3.

Results: The intensity of the lesions was lower in the r-IPC than in the H/R group, showing significant difference $(p<0.01)$. The $r$-IPC group showed a higher proliferative activity compared to the H/R group $(p<0.01)$, with deeper crypts $(r-I P C>H / R-p<0.05)$, and higher villi, showing significant difference ( $r$-IPC $>H / R-(p<0.01)$. The occurrence of apoptosis in the $H / R$ group was lower in comparison to groups $C$ and $r$-IPC, with significant difference $(H / R<$ r-IPC; $\mathrm{p}<0.05$ ).

Conclusion: The remote ischemic preconditioning applied to the pregnant rat protected the ileum of newborn rats subjected to hypoxia and reoxygenation, with decreased intensity of the lesions in the ileum mucosa and preservation of proliferative activity, keeping the villus height and crypt depth similar to group C.

Key words: Enterocolitis, Necrotizing. Ischemic Preconditioning. Pregnancy, Animal. Rats. 


\section{- Introduction}

Necrotizing enterocolitis (NEC) is the main cause of morbidity and mortality in very low birth weight neonates ${ }^{1,2}$. Due to an unsatisfactory response to treatment and lack of effective prevention, it is estimated that $20 \%$ to $40 \%$ of newborns with NEC require surgical treatment ${ }^{2}$.

Multiple factors contribute to the pathophysiology of NEC, such as intestinal immaturity, which involves the digestive system motility, the ability to perform digestion, blood flow regulation, mucosal barrier function and intestinal immunity. Intestinal mucosal stress related to ischemia, abnormal bacterial colonization, and onset of feeding are also involved ${ }^{3,4}$ Intestinal ischemia clearly occurs, with histopathological evidence such as inflammatory cell infiltration, edema, ulceration and coagulative necrosis. Some factors are frequently associated to ischemic events in the development of NEC, such as perinatal hypoxia, cyanotic congenital heart diseases, polycythemia, umbilical catheterization, respiratory stress syndrome, and the use of drugs that decrease the upper mesenteric artery blood flow ${ }^{5}$.

The search for strategies that lead to protection in the prenatal period, in order to prevent or minimize intestinal ischemia and reperfusion (IR) lesions in the newborn is a challenge. Remote Ischemic Preconditioning ( $r$-IPC) has shown protective effect of different organs submitted to ischemia and reperfusion ${ }^{6-9}$. Humoral and neuronal mediators are involved in their mechanism of action, leading to transfer and storage of information to a main pathway, which increases cell tolerance to subsequent ischemic injury ${ }^{8-10}$. It has been shown that r-IPC is a modality in which protection will occur at a distance from the ischemic organ, through the release of biochemical messengers into the circulation or through the activation of nerve pathways, resulting in a protective effect against IR lesions ${ }^{11,12}$. The r-IPC could be performed by clamping of blood vessels directly or with a tourniquet around the limb with skeletal muscle ischemia ${ }^{10}$.

The characteristic of $r$-IPC is the occurrence of two distinct phases of protection: early, which begins immediately after reperfusion, having protective action in a period of two to three hours, and the late one, which manifests itself between twelve and twenty-four hours after the initial reperfusion, acting for up to 72 hours ${ }^{6,12}$.

In our lab, it was shown that r-IPC applied on pregnant rat minimized the occurrence of colonic NEC in their pups ${ }^{13}$. Considering the systemic effect of $r$-IPC against IR lesions and that ischemia is a relevant factor in the occurrence of NEC; further, the ileum is also compromised in this disease; it was decided to test the hypothesis that $r$-IPC applied in pregnant rat might attenuate the small bowel lesions in an experimental NEC model.

\section{Methods}

The experiments were conducted after approval by the Research Ethics Committee, Universidade Federal de São Paulo, under protocol no. CEP 0341/07.

It was used three pregnant rats and their 31 newborns from the OUTBRED EPM1 Wistar strain (Rattus norvegicus albinus, Rodentia mammalia) from the National Institute of Pharmacology, UNIFESP. Three groups were included in this study: -Control (C): newborns rats that did not undergo any intervention ( $n=10)$; -Hypoxia/Reoxygenation $(\mathrm{H} / \mathrm{R})$ : newborns rats underwent hypoxia and reoxygenation $(n=9)$; - Remote Ischemic Preconditioning ( $r-I P C)$ : remote ischemic preconditioning 24 hours before birth, and 
hypoxia-reoxygenation in the newborn rats.

\section{Pregnancy criteria}

After one night mating, the animals that presented vaginal smears with the presence of spermatozoa in the morning were considered potentially fertilized. The day of birth of the pups was determined from this day (D0-zero day of pregnancy), counting another 20 days for the date of birth (D21 - twenty-first day of pregnancy).

\section{Protocol for remote ischemic preconditioning $(r-I P C)$}

All the pregnant rats were submitted to anesthesia with intramuscular injection a solution of Ketamine (50mg / kg) and Xylazine (10mg / kg).

The pregnant rat of the r-IPC group was submitted to the remote ischemic preconditioning by means of a tourniquet with an elastic band in the proximal region of the left hind paw, being submitted to ischemia for 10 minutes and the tourniquet being withdrawn after this time, allowing reperfusion ${ }^{11}$. The left paw plantar region became cyanotic, and the right one was pinkish, showing adequate perfusion pattern.

\section{Hypoxia and reoxygenation protocol}

The NEC model used was described by Ozkan et al. ${ }^{14}$. The animals of the $H / R$ and $r$-IPC groups were submitted to hypoxia in a carbon dioxide $\left(\mathrm{CO}_{2}\right)$ chamber, where they received a gas stream containing 100\% CO2 for 10 minutes. After hypoxia, the animals received oxygen-containing gas $\left(\mathrm{O}_{2}\right)$ at $100 \%$ for 10 minutes. After this procedure, the newborn rats were kept with their respective mothers in a normothermic environment. All animals received breast milk before and after treatment.

\section{Euthanasia}

All newborn animals were submitted to cervical displacement for euthanasia on the fourth day of life.

\section{Histopathology}

Samples of the terminal ileum were collected one $\mathrm{cm}$ from the ileocecal valve, which were prepared for histological analysis and immunohistochemistry. The fragments were fixed in $10 \%$ formaldehyde solution for 16 hours, and then transferred to $70 \%$ alcohol and, after 24 hours, the material was embedded in paraffin. After inclusion in paraffin, four micrometer sections were made and staining with Hematoxylin-Eosin (HE). Under optical microscopy, the pathologist did the blinded histopathological analysis applying the Chiu et al. ${ }^{15}$ classification for grading intestinal injury.

\section{Protocol for Ki67}

Slides prepared for HE-staining and the immunohistochemistry came from the same block. Cells labeled by Ki67 were considered positive and counted within the crypts. The villi size was determined by measuring from the crypt base to the villus surface, based on the histological description of the mucosal components. The counting was performed on the labeled slides, analyzing 5 to 10 crypts in each slide, in a field of magnification of 20x, modified from Vieten et al. ${ }^{16}$.

\section{Protocol for cleaved Caspase-3}

It was used rabbit monoclonal antibody anti-cleaved caspase-3, clone 5A1E - Cell Signaling Technology ${ }^{\circledR}$. The number of apoptotic bodies was counted by the pathologist, without prior knowledge of the group to which each animal belonged. The scale for the quantification of the apoptotic corpuscles was done as described previously 
17 as follows: Grade 0 - 0 to 2 labeled cells; Grade 1 - 3 to 5 labeled cells; Grade 2 - 6 to 20 labeled cells; Grade 3 - from 21 to 50 labeled cells; Grade 4 - 51 cells or more marked by cleaved caspase-3.

All images and measurements were obtained using the Axion Vision REL 4.6 - Carl Zeiss.

\section{Statistical analysis}

Analysis of Variance (ANOVA) was used for independent samples - analysis of one variable. Differences were found by Tukey's multiple comparison tests. The non-parametric Kruskal-Wallis test was applied for independent samples in the analysis of apoptosis occurrence. The differences are consistent with Dunn's multiple comparison tests. The differences were considered significant with $p<0.05$.

\section{- Results}

Maternal r-IPC preserved the intestinal villi $(p<0.0001)$, with the occurrence of $75 \%$ of grades 1 and 2, while in the Hypoxia/ reoxygenation group, grades 3 and 4 lesions occurred in $67 \%$ of the newborn rats (Figure 1 ).

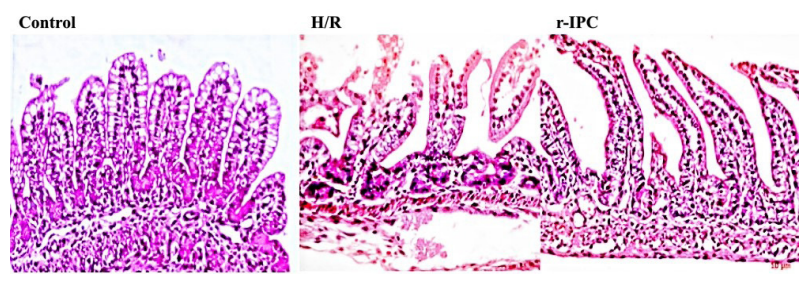

Figure 1 - Photomicrographs showing histopathological aspects of intestinal injury for each group: Control (Grade 0); H/R (Grade III); r-IPC (Grade II) (x200).

Proliferative activity by Ki67, villi height and crypt depth

Expression of Ki-67 was normal in all animals of the Control group, in contrast to the Hypoxia/Reoxygenation group (Median of positive cells $\mathrm{C}=14 \quad(10-15) ; \mathrm{H} / \mathrm{R}=8$ (012); $r I P C=12$ (11-14); r-IPCvsH/R, $p=0.0002)$, which, in addition, showed decreased crypt depth and villus height. The remote ischemic preconditioning preserved the proliferative activity, as well the depth of the crypts $(\mathrm{C}=29$ $\mu \mathrm{m} ; \mathrm{H} / \mathrm{R}=16 \mu \mathrm{m} ; \mathrm{rIPC}=24 \mu \mathrm{m}, \mathrm{r}-\mathrm{IPCvsH} / \mathrm{R}$, $\mathrm{p}=0.01)$ and villus height $(\mathrm{C}=87 \mu \mathrm{m}, \mathrm{H} / \mathrm{R}=45$ $\mu \mathrm{m} ; \mathrm{r}-\mathrm{IPC}=84 \mu \mathrm{m}, \mathrm{r}-\mathrm{IPC} v \mathrm{HH} / \mathrm{R}, \mathrm{p}=0.01$ ) (Figure 2).

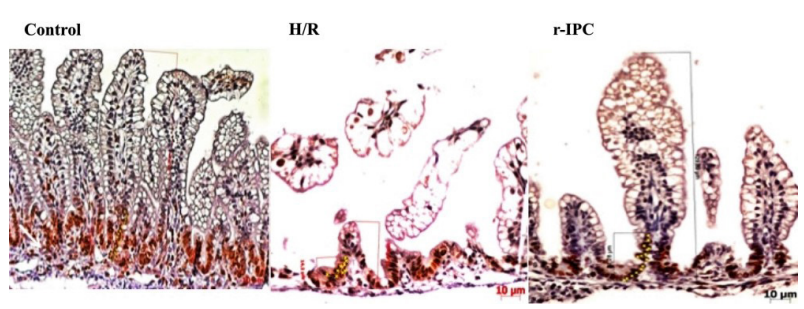

Figure 2 - Photomicrographs showing villus height and crypt depth for studied groups: Control, H/R, and $r-I P C(x 200)$.

\section{Apoptosis by Cleaved-Caspase-3}

Apoptosis was basal in the Control group, in contrast to the Hypoxia/Reoxygenation group (Mean of apoptotic bodies $\mathrm{C}=12 ; \mathrm{H}$ / $\mathrm{R}=1 ; \mathrm{rIPC}=5 ; \mathrm{r}-\mathrm{IPC} v \mathrm{H} / \mathrm{R}, \mathrm{p}=0.001$ ). The remote ischemic preconditioning improved apoptosis occurrence compared to H/R (Figures 3 and 4).

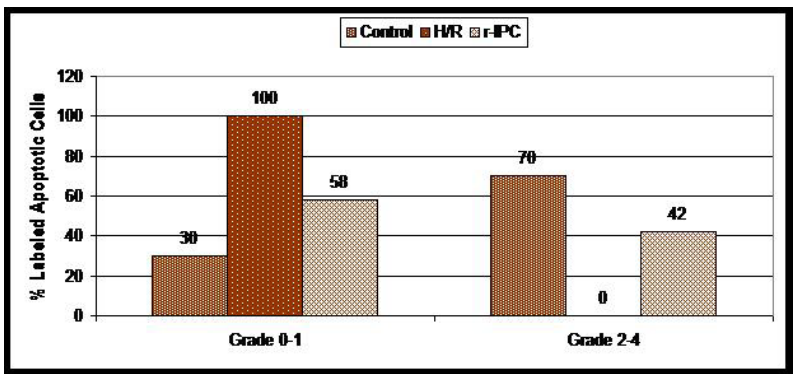

Figure 3 - Occurrence of apoptosis, expressed as \%, in the different studied groups. Teste de comparações múltiplas de Dunn - Kruskal-Wallis $r-I P C v s H / R, p=0.05$. 


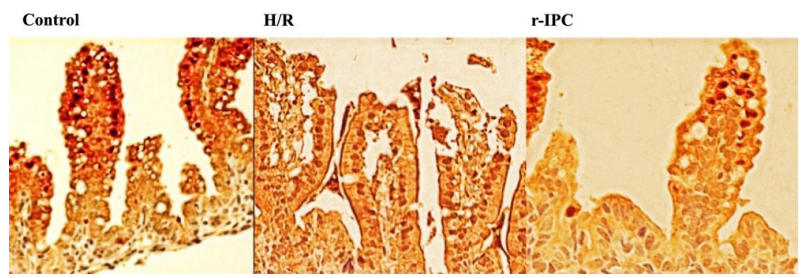

Figure 4 - Photomicrographs showing different degrees of apoptosis in the studied groups: Control, $H / R$, and $r-I P C(x 200)$.

\section{- Discussion}

The r-IPC applied into a pregnant rat brought benefits to their pups subjected to $H / R$ after birth, reducing the occurrence of the ileum lesions observed in the NEC model, regarding histopathological, proliferative activity and apoptosis.

The intestinal mucosa is particularly susceptible to ischemia and reperfusion injury, occurring after hypovolemic shock, septic shock, or even associated with necrotizing enterocolitis ${ }^{17}$. Experimental models that use hypoxia reduce intestinal perfusion, an important factor in the etiopathogenesis of ischemic bowel diseases ${ }^{18}$.

Regarding the model of induction of NEC, previously in our laboratory ${ }^{3,19}$ it was used the model described by Okur et al. ${ }^{18}$, obtaining the same degree of injury. However, for the present study, we had to move to the model described by Ozkan et al. ${ }^{14}$, to obtain the expected intestinal injury, probably due to the weight of the animals, which were larger than the previously used.

Different models of $r$-IPC have been used to avoid ischemia reperfusion injury. Regarding the experimental model of r-IPC, the application of the tourniquet to the pregnant rat's paw is an efficient model to cause ischemia ${ }^{11}$.

Remote ischemic preconditioning promotes tissue protection by two ways of action: the neuronal and the humoral ${ }^{8,9,20}$. In the present study, the protective mechanism was probably humoral, since maternal-fetal interaction occurs through the placenta, the basic site of nutrient and gas exchanges between the mother and the fetus. This interaction is performed through a vascular network created by the expression of the transcription factor glial cells missing - 1, which inhibits the formation of neurons ${ }^{21}$.

Grande et al. ${ }^{6}$ described the two periods and the magnitude of protection conferred by both IPC and r-IPC: the early and late protection period. The induction of hypoxia and reoxygenation occurred within the second protection period, which lasts from three to four days. This observation allows us to assume that the mechanisms involved in the protection observed by r-IPC in our study are related to this late phase of action, mainly involving the synthesis of proteins such as heat shock proteins, nitric oxide synthase.

The proliferative response of the intestinal epithelium, in the presence of NEC, has been poor studied. Vieten et al. ${ }^{16}$ observed that in NEC there is a deficiency of the proliferative activity, incapacitating the neutralization of the rapid epithelium destruction, also associated with the intestinal immaturity of the preterm infants. Corroborating these findings, it was observed a deficiency of the proliferative activity in the intestinal mucosa of the H/R group. However, puppies from mothers who underwent $r$-IPC during pregnancy maintained proliferative activity in the intestinal mucosa similarly to Control group puppies. The inability of mucosal regeneration in preterm infants may be related to the deficiency of the expression of the peptide trefoil factor, present in mucus and released together with mucin by goblet cells, contributing to the etiopathogenesis of NEC. Trefoil factor plays an important role in the intestinal epithelium, participating in its protection, its restitution and its regeneration ${ }^{16}$.

In the physiological process of intestinal mucosa renewal, in addition to cell proliferation, the process of apoptosis of epithelial cells also occurs $^{22}$. Jilling et al. ${ }^{22}$ evaluated apoptosis in 
the gut of newborn rats, demonstrating that it was already present at a time prior to the onset of necrosis and that the frequency of apoptosis was lower in animals with higher injury degree of the intestinal mucosa. The r-IPC preserved the physiological activity of apoptosis in the analysis by caspase-3-cleaved, similarly to what was observed in the animals of the Control group. The opposite occurred in the H/R group in which there was intense cellular injury, leading to villi destruction and necrosis of the intestinal mucosa. Thus, the higher occurrence of apoptosis due to r-IPC denotes its protective effect, with preservation of the intestinal mucosa, reducing the severity of the lesion. The mucosa of the ileum remained with physiological characteristics, identifying the apoptotic bodies at the end of the villi, where the epithelium flakes into the intestinal lumen in the cell renewal process ${ }^{22,23}$. Therefore, apoptosis was not a pathological event, but a marker of physiological response demonstrating the modulation performed by r-IPC.

The benefit observed in the ileum of newborn rats from pregnant submitted to r-IPC is the fundamental contribution of the present study. However, the limitation of the model in identifying the humoral factors that have surpassed the placental barrier should be object of new research.

\section{Conclusion}

The remote ischemic preconditioning applied to the pregnant rat protected the ileum of newborn rats subjected to hypoxia and reoxygenation, with decreased intensity of the lesions in the ileum mucosa and preservation of proliferative activity, keeping the villus height and crypt depth.

\section{References}

1. Schnabl KL, van Aerde JE, Thomson AB, Clandinin MT. Necrotizing enterocolitis: a multifactorial disease with no cure. World
J Gastroenterol. 2008;14(14):2142-61. doi: 10.3748/wjg.14.2142.

2. Petrosyan M, Guner YS, Williams $M$, Grishin $A$, Ford HR. Current concepts regarding the pathogenesis of necrotizing enterocolitis. Pediatr Surg Int. 2009;25(4):309-18. doi: 10.1007/s00383-009-2344-8.

3. Meyer KF, Martins JL, Freitas Filho LG, Oliva ML, Patrício FR, Macedo M, Wang L. Evaluation of an experimental model of necrotizing enterocolitis in rats. Acta Cir Bras. 2006;21(2):113-8. PMID: 16583065.

4. Choi YY. Necrotizing enterocolitis in newborns: update in pathophysiology and newly emerging therapeutic strategies. Korean J Pediatr. 2014;57(12):505-13. doi: 10.3345/ kjp.2014.57.12.505.

5. Zani A, Eaton S, Leon FF, Malerba A, Hall NJ, De Coppi P, Smith VV, Pierro A. Captopril reduces the severity of bowel damage in a neonatal rat model of necrotizing enterocolitis. J Pediatr Surg. 2008;43(2):308-14. doi: 10.1016/j. jpedsurg.2007.10.022.

6. Grande L, Roselló-Catafau J, Peralta C. El preacondicionamiento isquémico del hígado: de las bases moleculares a la aplicación clínica. Cir Esp. 2006;80(5):275-82. doi: 10.1016/ S0009-739X(06)70970-8.

7. Limani $P$, Linecker $M$, Oberkofler CE, Barmettler G, Kaech A, Graf R, Humar B, Clavien PA. remote ischemic preconditioning: a novel strategy in rescuing older livers from ischemiareperfusion injury in a rodent model. Ann Surg. 2016;264(5):797-803. PMID: 27584570.

8. Saxena P, Newman MA, Shehatha JS, Redington AN, Konstantinov IE. Remote ischemic conditioning: evolution of the concept, mechanisms, and clinical application. J Card Surg. 2010;25(1):127-34. doi: 10.1111/j.15408191.2009.00820.x.

9. Tapuria N, Kumar Y, Habib MM, Abu Amara $M$, Seifalian AM, Davidson BR. Remote ischemic preconditioning: a novel protective method from ischemia reperfusion injury--a review. J Surg Res. 2008;150(2):304-30. PMID: 19040966.

10. Kocman EA, Ozatik O, Sahin A, Guney T, Kose AA, Dag I, Alatas O, Cetin C. Effects of ischemic preconditioning protocols on skeletal muscle ischemia-reperfusion injury. J Surg Res. 2015;193(2):942-52. doi: 10.1016/j. jss.2014.09.032. PMID: 25438960.

11. Souza Filho MV, Loiola RT, Rocha EL, Simão AF, 
Gomes AS, Souza MH, Ribeiro RA. Hind limb ischemic preconditioning induces an antiinflammatory response by remote organs in rats. Braz J Med Biol Res. 2009;42(10):921-9. PMID: 19738981.

12. Mallick IH, Winslet MC, Seifalian AM. Ischemic preconditioning of small bowel mitigates the late phase of reperfusion injury: heme oxygenase mediates cytoprotection. Am J Surg. 2010;199(2):223-31. doi: 10.1016/j. amjsurg.2009.01.011.

13. Freitas MAL, Gomes ROL, Soares BLF, Artigiani-Neto R, Montero EFS, Martins JL. Effects of maternal ischemic preconditioning in the colon of newborn rats submitted to hypoxia-reoxygenation insult. Acta Cir Bras. 2014;29(7):438-44. doi: 10.1590/S0102865020140007000051.

14. Ozkan KU, Ozokutan BH, Inanç F, Boran C, Kilinç $M$. Does maternal nicotine exposure during gestation increase the injury severity of small intestine in the newborn rats subjected to experimental necrotizing enterocolitis. J Pediatr Surg. 2005;40(3):484-8. doi: 10.1016/j. jpedsurg.2004.11.040.

15. Chiu CJ, McArdle AH, Brown R, Scott HJ, Gurd FN. Intestinal mucosal lesion in low-flow states. Arch Surg. 1970;101:478-83. PMID: 5457245.

16. Vieten D, Corfield A, Ramani P, Spicer R. Proliferative response in necrotising enterocolitis is insufficient to prevent disease progression. Pediatr Surg Int. 2006;22(1):506. doi: 10.1007/s00383-005-1588-1.

17. Moore-Olufemi SD, Olufemi SE, Lott S, Sato N, Kozar RA, Moore FA, Radhakrishnan RS, Shah $\mathrm{S}$, Jimenez $\mathrm{F}$, Kone BC, Cox CS Jr. Intestinal ischemic preconditioning after ischemia/ reperfusion injury in rat intestine: profiling global gene expression patterns. Dig Dis Sci.
2010;55(7):1866-77. doi: 10.1007/s10620009-0980-4.

18. Okur $H$, Küçükaydin $M$, Köse $K$, Kontaş $O$, Doğam $P$, Kazez A. Hypoxia-induced necrotizing enterocolitis in the immature rat: the role of lipid peroxidation and management by vitamin E. J Pediatr Surg. 1995;30(10):1416-9. PMID: 8786477.

19. Cintra $A E$, Martins JL, Patrício FR, Higa EM, Montero EF. Nitric oxide levels in the intestines of mice submitted to ischemia and reperfusion: L-arginine effects. Transplant Proc. 2008;40(3):830-5. doi: 10.1016/j. transproceed.2008.02.044.

20. Kanoria S, Jalan R, Seifalian AM, Williams R, Davidson BR. Protocols and mechanisms for remote ischemic preconditioning: a novel method for reducing ischemia reperfusion injury. Transplantation. 2007;84(4):445-58. doi: 10.1097/01.tp.0000228235.55419.e8.

21. Hitoshi S, Ishino $Y$, Kumar A, Jasmine S, Tanaka KF, Kondo T, Kato S, Hosoya T, Hotta Y, Ikenaka K. Mammalian $\mathrm{Gcm}$ genes induce Hes5 expression by active DNA demethylation and induce neural stem cells. Nat Neurosci. 2011;14(8):957-64. doi: 10.1038/nn.2875.

22. Jilling T, Lu J, Jackson M, Caplan MS. Intestinal epithelial apoptosis initiates gross bowel necrosis in an experimental rat model of neonatal necrotizing enterocolitis. Pediatr Res. 2004;55(4):622-9. doi: 10.1203/01. PDR.0000113463.70435.74.

23. Lugo-Martínez VH, Petit CS, Fouquet S, Le Beyec J, Chambaz J, Pinçon-Raymond M, Cardot $\mathrm{P}$, Thenet S. Epidermal growth factor receptor is involved in enterocyte anoikis through the dismantling of E-cadherinmediated junctions. Am J Physiol Gastrointest Liver Physiol. 2009;296(2):G235-44. doi: 10.1152/ajpgi.90313.2008.
Correspondence:

José Luiz Martins

Rua dos Otonis, 131

04025-000 São Paulo - SP Brasil

Tel./Fax: (55 11)5575-4761

jlmartins1@terra.com.br

Received: Nov 21, 2016

Review: Jan 23, 2017

Accepted: Feb 24, 2017
Conflict of interest: none

Financial source: none

${ }^{1}$ Research performed at Laboratory of Research in Pediatric Surgery, Universidade Federal de São Paulo (UNIFESP), Brazil. Part of PhD degree thesis, Postgraduate Program in Interdisciplinary Surgical Science, UNIFESP. Tutor: José Luiz Martins. 